\title{
Editorial Special Issue in Honor of Shlomo Magdassi-Bringing Basic
Colloid Science into Industrial Products
}

\author{
Alexander Kamyshny ${ }^{1, *}$ and Victor M. Starov ${ }^{2}$ (D) \\ 1 Casali Center for Applied Chemistry, Institute of Chemistry, Faculty of Mathematics and Sciences, \\ The Hebrew University of Jerusalem, Jerusalem 91904, Israel \\ 2 Chemical Engineering Department, Loughborough University, Loughborough LE11 3TU, UK; \\ v.m.starov@lboro.ac.uk \\ * Correspondence: alexander.kamyshny@mail.huji.ac.il
}

Citation: Kamyshny, A.; Starov, V.M. Special Issue in Honor of Shlomo Magdassi-Bringing Basic Colloid Science into Industrial Products. Colloids Interfaces 2021, 5, 32. https://doi.org/10.3390/colloids 5020032

Received: 8 April 2021

Accepted: 4 June 2021

Published: 8 June 2021

Publisher's Note: MDPI stays neutral with regard to jurisdictional claims in published maps and institutional affiliations.

Copyright: (c) 2021 by the authors. Licensee MDPI, Basel, Switzerland. This article is an open access article distributed under the terms and conditions of the Creative Commons Attribution (CC BY) license (https:// creativecommons.org/licenses/by/ $4.0 /)$.

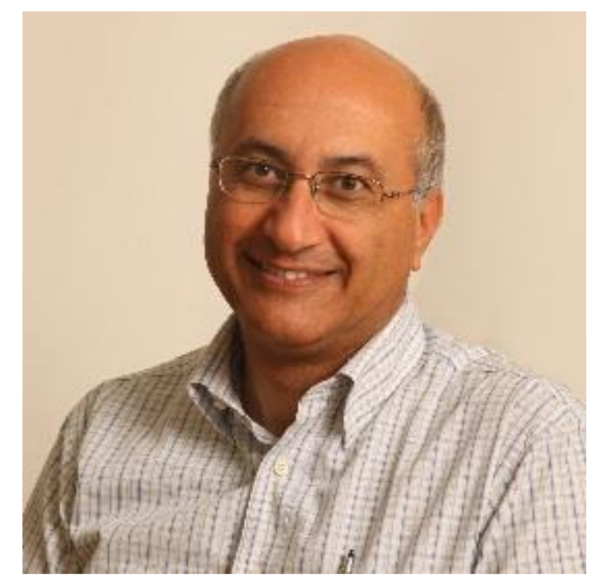

The majority of basic research that is conducted by Prof. Shlomo Magdassi in materials science, and especially in colloids and interface science, is driven by his intuition, natural curiosity, and the potential for industrial applications. Shlomo is a prolific scientist who, in addition to his impressive publication record, has a remarkable ability to bring academic research into the world of commercial products, industrial processes, and establishing start-up companies.

Shlomo studied chemistry at the Hebrew University (1975-1978), followed by master and doctoral degrees in applied chemistry, also at The Hebrew University of Jerusalem under the supervision of Prof. Nissim Garti (MSc. 1978-1980 and PhD. 1980-1984). After his PhD studies, Shlomo was a post-doc fellow for about two years at the Ohio State University, with Prof. Sylvan Frank, in the School of Pharmacy. His early research focused on the formation and stabilization of various emulsions. In 1985, Shlomo received a faculty position at The Hebrew University in Applied Chemistry, where he holds a Professor position at The Institute of Chemistry. Shlomo is the former head of the Institute of Chemistry (2016-2019) and is currently the Director of the Centre for Functional and 3D Printing and holds the Enrique Berman Chair in solar energy at The Hebrew University of Jerusalem.

His current research focuses on the preparation of colloidal systems and formulations. Often, the colloidal systems he chooses to investigate originate from an unmet need and a question of "what can it be good for?". His deep knowledge in emulsions, nanomaterials, and interfacial phenomena has led to unique scientific findings and applications in a variety of fields. When asked what the connection between the various fields of applications is, Shlomo likes to give the following answer: if you make an emulsion or a dispersion, you can drink it, and then it is a food supplement or an oral drug. You can put it on your 
face, so it is a cosmetic or a topical drug delivery system. If you spray it on a wall, it is a paint or a coating, and if you place it on paper it is an ink. Of course, there are many differences between the resulting materials, according to the requirements, restrictions, and regulations, but the basic scientific understanding of making such systems and tailoring their properties is the most important criteria for success.

In recent years, Shlomo has focused on materials that have importance in two main fields that he has a passion for: delivery systems and functional printing. In the first field, Shlomo has developed several new processes to make nanoparticles of water-insoluble materials such as drugs, and nanoemulsions. These particles were prepared, for example, by utilizing a solvent evaporation process with microemulsions composed of volatile solvents and dissolved active material. Upon lyophilization or spray drying, a powder is obtained, which upon contact with water disperses spontaneously to yield a dispersion of organic nanoparticles. A vast amount of Shlomo's work is inspired by simple observations of colloidal phenomena and nature. For example, several years ago he developed a nanoemulsion of pomegranate oil with a unique antioxidation property, based on the well-known Ouzo effect of self-emulsification while mixing the Greek drink with water.

The second of his beloved fields of research is coatings and functional printing. Scientifically, this combines preparation and stabilization of colloidal systems, synthesis of particles, such as metals and ceramic by polymerization, sol-gel processes and chemical reduction, wetting phenomena, and formulations. For example, Shlomo investigated the formation of heat-resistant dispersions of inorganic pigments and carbon nanotubes as a solar absorber, which can be utilized as black absorber coatings for energy harvesting. The developed coating formulations are currently used in the largest thermo-solar plant in the world, producing energy for over 100,000 houses in California. In the field of printing, Shlomo has worked extensively on the synthesis of silver and copper nanoparticles for utilization as conductive inks for printed electronics. Two unique findings are related to the metallic particles. The first is the discovery that silver nanoparticles can be sintered at room temperature, by a simple ligand exchange mechanism, a finding that was extended to a combination of particles, such as gold and silver. The second one points out his intuition; a major problem in ink applications related to the coffee-ring effect. While observing this phenomenon, Shlomo came to the idea of converting the problem into a solution. He utilized the coffee-ring effect to form invisible rings composed of silver nanoparticles, which, after room temperature sintering, were converted into an array of transparent rings. This array is applied as a transparent conductive electrode, which is important for the field of optoelectronic devices as a replacement of indium tin oxide (ITO).

Repeating the 2D printing again and again brings it to the field of 3D printing. Here he published important results on printing stretchable objects by Digital Light Processing and on printing ceramic materials, such as silica and yttrium aluminium garnet (YAG) at submicron resolutions, while the internal structure of the latter was imaged at atomic resolution. From 3D printing, Shlomo moved to the emerging field of 4D printing, which is printing objects that change their shape upon triggering. For his contributions to nanoscience by the development of nanoparticle-based methods and approaches to functional printing, 3D printing, and drug delivery with potential applications in plastic electronics, conductive printing and medical applications, Prof. Shlomo Magdassi obtained the ECIS-Solvay Prize 2016 of the European Colloid and Interface Society.

Prof. Magdassi is a well-known scientist and is often invited to give keynote lectures. He has many international research collaborations with scientists, especially from Europe and Singapore, and he participates in many European research consortiums. His research group is currently very active, which comes as no surprise as Shlomo is a great mentor; since he joined The Hebrew University, he has been the advisor of 79 MSc students, $24 \mathrm{PhD}$ students, and 20 post-doctoral fellows.

Now some numbers which represent the outcome of his work in a more quantitative way: Shlomo is the author of over 300 publications, over 20 chapters in books, and he is the editor of 4 books: Surface Activity of Proteins, Novel Cosmetic Delivery Systems, The Chemistry 
of Inkjet Inks, and Nanomaterials for $2 D$ and $3 D$ Printing. His work is well cited, having an $\mathrm{H}$ index of 69, (by Google Scholar) with 19,119 citations, and H index of 52, (by ISI), with 10,628 citations. For more info see: https://scholars.huji.ac.il/magdassi.

Shlomo also has more than 80 inventions (40 US granted patents, over 300 PCT international patent applications), which are related to applications of dispersed systems. Based on his inventions, many commercial activities have evolved, which has led to various licensing agreements, worldwide sales, and the establishment of new start-up companies. Among them are GlassJet inks (Dip-Tech), Silver nano-ink (Nanodimension, XjetSolar), Thermosolar coating (BrightSource Energy), Nanodroples (Granalix), Dead-Sea Gel, and Dead Sea Nanoparticles (Ahava).

Dear Shlomo, we, as well as the editor-in-chief and all the contributors, wish you to continue to be so active and enthusiastic in your future endeavours.

Conflicts of Interest: The authors declare no conflict of interest. 